\title{
Unsteady RANS Simulation of Air Distribution in a Ventilated Classroom with Numerous Jets
}

\author{
Nikolay Ivanov 1,*, Marina Zasimova ${ }^{1}$, Evgueni Smirnov ${ }^{1}$, Alexey Abramov ${ }^{1}$, Detelin Markov ${ }^{2}$ and Peter Stankov ${ }^{2}$ \\ ${ }^{1}$ Peter the Great St. Petersburg Polytechnic University, 29 Polytechnicheskaya str., St. Petersburg, 195251, Russia \\ ${ }^{2}$ Technical University of Sofia, 8 Kliment Ohridsky boulevard, Sofia, 1000, Bulgaria
}

\begin{abstract}
The study is devoted to the Unsteady Reynolds-Averaged Navies-Stokes (URANS) simulation of ventilation in an isothermal room with numerous jets supplied from ceiling diffusers. The computations of the airflow under the test conditions considered were carried out in the classroom of the Technical University of Sofia with no occupants. The room floor has a simple rectangular form, but several columns, beams, window sills, and four radiators are located inside the room that makes the geometry more complex. Air is supplied to the room through four ceiling fan coils, the Reynolds number is $2 \times 10^{4}$. Calculations were carried out using the ANSYS Fluent 18.2 software with the standard $k$ - $\varepsilon$ turbulence model chosen. Computational meshes of up to 33 million hexahedral cells clustered to the inlet and outlet sections were used. The main aim of the study presented is to analyze and discuss the complicated 3D flow structure in the room and to give foundation for future measurements of air velocity field in the room.
\end{abstract}

\section{Introduction}

The Indoor Air Quality (IAQ) control is of key importance in the design of Heating, Ventilation and Air Conditioning (HVAC) systems. The requirements for the HVAC systems design are based on keeping a certain level of air speed and temperature in the ventilated space, as well as contaminant source control and efficient contaminant removal. There are several recognized standards for ventilation system design and acceptable IAQ, such as American Society of Heating, Refrigerating and Air-Conditioning Engineers (ASHRAE) standard [1] or European standard [2]. To satisfy the IAQ standard, it is necessary, in particular, to define the required level of ventilation in air changes per hour or the outside air supply rate that is sufficient to prevent formation of large stagnant zones, to keep the temperature values within the prescribed range, and to limit the air pollution level.

To comply with these requirements from integral point of view, simplified lumped-parameters approaches are applied successfully for design and optimization of HVAC systems (see, e.g., [3]). These approaches use simplified analytical and empirical models and provide information on mass-averaged parameters in the ventilated room. Along with these methods, Computational Fluid Dynamics (CFD) simulation has become widely used in HVAC industry. Started in late nineties, the CFD techniques application has been continuing to rise during the last two decades. Opposite to simplified approaches, CFD modeling of turbulent indoor airflow allows to produce detailed threedimensional (3D) field information on air quality, e.g., size and location of stagnation and high-velocity zones, peculiarities of temperature distributions with respect to gradient values and location, as well as spatial and temporal information on contaminant transport.

In engineering practice, CFD models based on the Reynolds-Averaged Navier-Stokes (RANS) equations solution are widely used due to moderate computational resources required. RANS approach has been applied to solve complex ventilation problems such as design of HVAC systems in airplane cabins $[4,5]$, indoor swimming pools $[6,7]$, a solar house [8], and an ice rink arena [9]. RANS-based CFD studies aimed at development of life support systems on board of the International Space Station (ISS), especially in case of off-nominal operation and other contingency scenarios, are presented, e.g., in [10-12]. RANS approach solves a set of transport equations obtained from the NavierStokes equations by means of the averaging procedure that results in the unknown Reynolds stress tensor emergence. To close the equations, the Reynolds stresses must be modeled, and the commonly used method is to apply the Boussinesq turbulent viscosity approximation [13]. To define the turbulent viscosity, a semi-empirical turbulence model should be involved. RANS results depend strongly on the particular turbulence model used, and the uncertainty due to the turbulence model influence could be very high, especially when a fully developed turbulent flow, e.g., a turbulent jet, combines with a moderate Reynolds number flow in one problem, that is typical for ventilation tasks [14]. Consequently, RANS solutions demand comprehensive validation. The validation of RANS results could be performed either using more accurate vortex-resolving approaches (Large

\footnotetext{
* Corresponding author: ivanov ng@spbstu.ru
} 
Eddy Simulation, LES, or Direct Numerical Simulation, DNS) or well-documented benchmark experimental data obtained in different test room configurations.

Vortex-resolving LES approach solves the filtered Navier-Stokes equations. In LES, large scales of motion are resolved directly, while small scales must be modeled with an appropriate subgrid-scale (SGS) model. LES application gives information on instantaneous components of velocity, $V_{\mathrm{x}}, V_{\mathrm{y}}$ and $V_{\mathrm{z}}$ (sure, the term "instantaneous" covers the resolved frequencies only). The overview and outlook of LES could be found in [15]. LES, being an eddy-resolving technique, requires for large computational resources. However, it gives more accurate prediction of turbulent flows, and with the development of the parallel computations becomes more and more popular not only in fundamental studies.

To validate the CFD results, it is necessary to compare the numerical data with the experimental benchmark data. Extended description of most representative mixing ventilation benchmark experiments with the correspondent reference list is given in [16]. Examples of well-documented experimental data are as follows. The most popular isothermal benchmark test is the $2 \mathrm{D}$ test by Nielsen et al performed in 1978 [17]. The test data on mean velocity and fluctuations measured with the Laser-Doppler Anemometry (LDA) are available in [17] and on the website http://www.cfd-benchmarks.com/. These data have been used in more than 50 papers for CFD validation during the last two decades. Most of the contributions presented RANS simulation results, and among others, $\mathrm{PhD}$ theses by Bennetsen [18] and Voight [19] provided the most complete sets of RANS data under conditions of the test [17]. Recent contributions [20,21] presented accurate RANS and wall-modeled LES (WMLES) data on mixing ventilation in the test room [17].

Another example of isothermal ventilation test flow for more complicated geometry is the configuration considered by Posner et al. in 2003 [22] where LDA and particle image velocimetry (PIV) measurements were performed in a room with a large flow obstruction. Experimental data for this test is limited - the velocity profiles are given only in two sections of the room near the jet zone. Detailed computational study compared the CFD and experimental data was performed in [23, 24] using both RANS [23] and LES [24] approaches.

Several tests deal with a single $3 \mathrm{D}$ jet supplied from a diffuser to the confined space. Mocikat et al. proposed one of the tests in 2003 [25]. The test room includes a huge obstacle that interrupt the jet propagation. The velocity measurements were obtained using LDA technique with an accuracy of about $1 \%$. RANS simulation of airflow under the test conditions was performed in [26], and pronounced unsteady effects were reported.

In mixing ventilation systems diffusers are often located at side walls, above the inhabitants, and it is necessary to predict correctly not only the jet behavior, but the interaction between the jet zone, characterized by high velocities, and the low-velocity zone of induced secondary flows (occupied zone). Recent experiments by
Hurnik et al. in 2015 [16, 27] are the only example of a $3 \mathrm{D}$ test for a room with a sidewall jet with pronounced division into the jet and occupied zones. 3D jet supplied from a rectangular sidewall diffuser was studied using the LDA measurements (two air velocity components were measured with the uncertainty lower than $5 \%$ ), while velocity fields in the occupied zone were measured with the omnidirectional low velocity thermal anemometers (LVTA) techniques. The full data set on velocity measurement results is provided in a special file attached to [27]. WMLES data of the side jet spreading in the confined space was compared with the velocity profiles in the jet zone [28] and in the occupied zone in [29], with special discussion of the mean velocity and mean speed difference.

The current paper presents results of the Unsteady Reynolds-Averaged Navies-Stokes (URANS) simulation of ventilation in an isothermal room with numerous jets supplied from ceiling diffusers. The main goal of the study is to analyze the complicated $3 \mathrm{D}$ flow structure in the room with jet interaction. The study will give foundation for future measurements of air velocity field in the room.

\section{Problem formulation}

\subsection{Geometry model}

The study covers airflow in the classroom at the Technical University of Sofia shown in Figure 1. The room has the following dimensions: the width of $W=5.4 \mathrm{~m}$ (along the $x$-axis), the length of $L=11.8 \mathrm{~m}$ (along the $y$-axis), and the height of $H=3.2 \mathrm{~m}$ (along the $z$-axis).

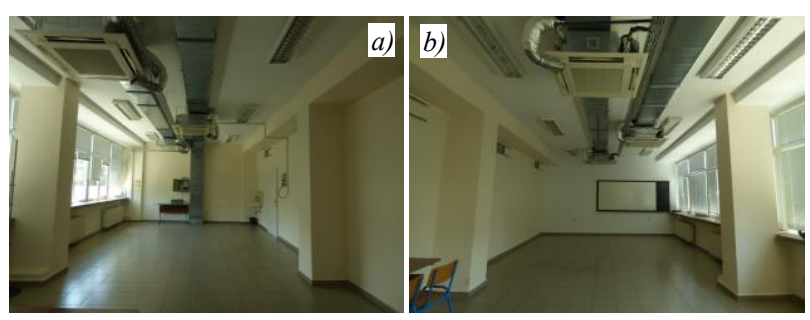

Fig. 1. Classroom at the Technical University of Sofia

The computational domain adopted for numerical simulation of the indoor ventilation problem is shown in Figure 2. The origin of the coordinate systems is located in the floor corner of the room (Figure 2). The geometry model includes the window sill along one of longitudinal wall, four radiators located under the window sill $\left(r_{1}-r_{4}\right.$ in Figure 2), four columns (I, II, III and IV in Figure 2), two ceiling beams placed in the corners of the room along the longitudinal direction, four ceiling diffusers (\#1 - \#4 in Figure 2) and corresponding ventilation ducts. All the elements are treated as rectangles and/or parallelepipeds, so that, if necessary, the shape of the elements included into the geometry model is simplified slightly.

The dimensions of the elements in the room are as follows. The window sill, with a width of $0.4 \mathrm{~m}$ and a 
height of $0.1 \mathrm{~m}$, is stretched along the side wall $x=0$, the width and the height of its base is equal to $0.1 \times 0.9 \mathrm{~m}$. All radiators have the same dimensions of $0.2 \times 1.5 \times 0.5 \mathrm{~m}$, the distance from the side-wall $y=0$ to the radiator $r_{1}$ is $0.7 \mathrm{~m}$, to $r_{2}-3.6 \mathrm{~m}$, to $r_{3}-6.7 \mathrm{~m}$, and to $r_{4}-9.6 \mathrm{~m}$; the distance from the floor to the bottom of each radiator is $0.2 \mathrm{~m}$. The left ceiling beam has the height of $h_{c, 1}=0.2 \mathrm{~m}$ and the width of $0.9 \mathrm{~m}$. The right ceiling beam has the height of $h_{c, 2}=0.4 \mathrm{~m}$ and the width of $0.6 \mathrm{~m}$.

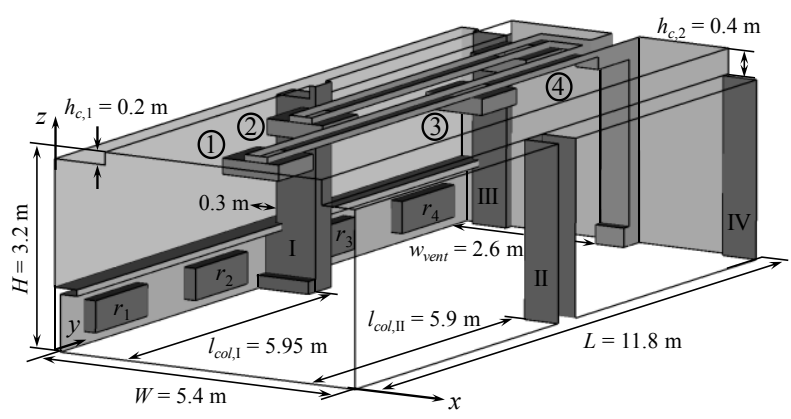

Fig. 2. Computational domain adopted for calculations

The height of the columns coincides with the height of the room. Column I with the length of $0.45 \mathrm{~m}$ is located at the distance $l_{c o l, \mathrm{I}}=5.95 \mathrm{~m}$ from the side wall $y=0$ and has a ledge with the dimensions of $0.2 \times 0.2 \mathrm{~m}$ near the floor. Under the window sill the width of column $\mathrm{I}$ is equal to $0.9 \mathrm{~m}$, the column here adjoins the window sill base without any gaps. Above the window sill there is a gap between the column and the adjacent wall $x=0$, the gap width is $0.3 \mathrm{~m}$, the width of the column here is equal to $0.7 \mathrm{~m}$. Column II with the width of $0.6 \mathrm{~m}$ and the length of $0.5 \mathrm{~m}$ is located near the opposite wall, $x=5.4 \mathrm{~m}$. The distance from the wall $y=0$ to the column II is equal to $l_{c o l, I I}=5.9 \mathrm{~m}$. Columns III and IV with the width of $0.6 \mathrm{~m}$ and the length of $0.15 \mathrm{~m}$ adjoin the wall $y=11.8 \mathrm{~m}$, and are located at the distances of $0.2 \mathrm{~m}$ and $4.5 \mathrm{~m}$ from the wall $x=0$.
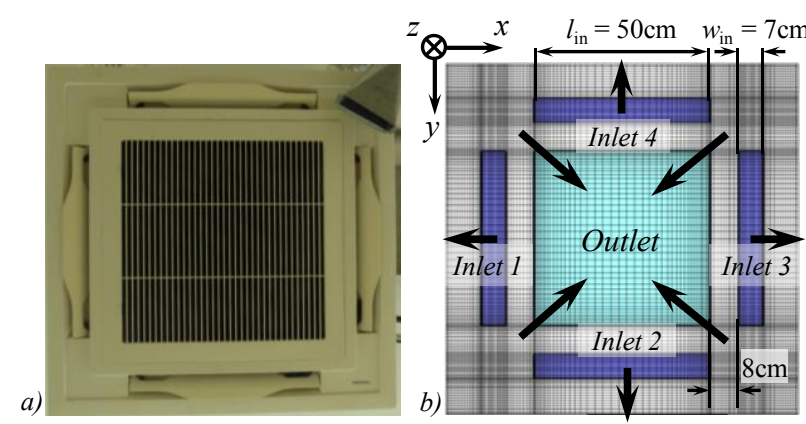

Fig. 3. Supply and exhaust diffuser: (a) the photo of the real diffuser and (b) the geometry model with the mesh (the case of 33 million cells)

The room is equipped with four conventional ceiling fan coils (or diffusers, marked as \#1 to \#4 in Figure 2). The size of each fan coil is $1 \times 1 \times 0.25 \mathrm{~m}$. The distance from the wall $x=0$ to fan coils \#2 and \#4 is equal to
$1.4 \mathrm{~m}$, the distance to fan coils $\# 1$ and $\# 3$ is equal to $2.4 \mathrm{~m}$; the distance from the side-wall $y=0$ to the fan coil \#1 is $1 \mathrm{~m}, \# 2-3.9 \mathrm{~m}, \# 3-6.9 \mathrm{~m}$, and \#4-9.8 $\mathrm{m}$.

As shown in Figure 3, each fan coil has four peripheral supply sections equipped with turning vanes and one central suction section. The supply sections are inlet openings for the computational domain shown in Figure 2, and the suction section is an outlet opening for the computational domain. The size of the suction section is $0.5 \times 0.5 \mathrm{~m}$. The size of each supply section is equal to $0.5 \times 0.07 \mathrm{~m}$; each supply section is placed at the distance of $0.08 \mathrm{~m}$ from the corresponding edge of the suction section. In total, the room includes four outlet openings and sixteen inlet openings.

Air is supplied to the fan coils by means of ventilation ducts shown in Figure 2. The airflow in the ducts is not considered in the current simulation, so that the ducts are just the obstacles for the airflow in the computational domain. The vertical duct with the width of $0.5 \mathrm{~m}$ and the length of $0.3 \mathrm{~m}$ adjoins the wall $y=11.8 \mathrm{~m}$ (it is located at the distance of $w_{\text {vent }}=2.6 \mathrm{~m}$ from the wall $x=0$ ). The fan coils are attached to the horizontal ventilation ducts with the height of $0.1 \mathrm{~m}$ extending along the ceiling.

\subsection{Airflow parameters}

Air was assumed as an incompressible fluid with constant physical properties taken at the temperature $15^{\circ} \mathrm{C} \quad\left(\rho=1.225 \mathrm{~kg} / \mathrm{m}^{3}, \quad \mu=1.8 \times 10^{-5} \mathrm{~kg} / \mathrm{m} \cdot \mathrm{s}\right)$. The uniform velocity distribution over the inlet section area was assumed, and the velocity value of $U_{\text {bulk }}=4.26 \mathrm{~m} / \mathrm{s}$ was set at each inlet section. The supply mass flow rate of $G=0.183 \mathrm{~kg} / \mathrm{s}$ was adopted $\left(G=\rho l_{\text {in }} w_{\text {in }} U_{\text {bulk }}\right)$, the correspondent volume flow rate is $Q=537.8 \mathrm{~m}^{3} / \mathrm{h}$. It was assumed that the turning vanes provide the flow angle of $45^{\circ}$. The Reynolds number calculated using the inlet width is equal to $R e=\rho w_{\text {in }} U_{\text {bulk }} / \mu=2 \times 10^{4}$ (if the hydraulic diameter is used as the length scale, $D_{\mathrm{h}}=0.1228 \mathrm{~m}$, the correspondent Reynolds number is $\left.R e_{\mathrm{Dh}}=3.6 \times 10^{4}\right)$. At the outlet boundaries, the pressure outlet boundary condition was set assuming the uniform pressure distribution. The no-slip boundary condition was set at the solid walls.

\subsection{Turbulence modeling}

Turbulent airflow in the room was computed using the Reynolds-Averaged Navies-Stokes approach. According to the literature data, for RANS simulation of ventilation problems, one of the $k-\varepsilon$ semi-empirical turbulence models is preferable. The standard $k-\varepsilon$ turbulence model coupled with the enhanced wall treatment option was adopted for the current computations. In this model, the turbulent viscosity is defined as $v_{\text {turb }}=\mathrm{C}_{\mu} k^{2} / \varepsilon$, where $k$ is turbulent kinetic energy, $\varepsilon$ is its rate of dissipation, and $\mathrm{C}_{\mu}=0.09$ is the model constant. It was not possible to get a steady-state solution, so that the unsteady RANS (URANS) approach was used.

To specify boundary conditions for turbulence characteristics the ratio of the turbulent to molecular 
viscosity of $v_{\text {turb }} / v=10$ and the turbulent intensity of $5 \%$ were set at each inlet section.

\subsection{Computational meshes}

The computational meshes were created with the ANSYS ICEM CFD 18.2 mesh generator. First, three quasi-structured meshes of the same sub-map topology consisted of hexahedral cells were generated. The total cell number for the coarse mesh was 5.9 million cells, for the baseline mesh - 10 million cells, and for the refined mesh -33 million cells. All meshes were nonuniform, with clustering to the inlet and outlet sections and to the walls. Figure $3 \mathrm{~b}$ illustrates the refined mesh at the fan coil surface. The mesh covers the inlet and outlet sections, and strong clustering is visible in the figure. The cells of the smallest size are located in the corners of the inlet and outlet sections: for the coarse and baseline meshes these cells have dimensions of $10 \times 10 \times 10 \mathrm{~mm}$, while for the refined mesh the dimensions are $3 \times 3 \times 3 \mathrm{~mm}$ (see Table 1 ).

Second, two polyhedral meshes consisted of 4.5 and 7 million mesh elements were generated. The computational domain at a distance from the diffusers was filled with almost equal polyhedral cells, the volume of each cells was equal to $\mathrm{Vol}_{\max }$; mesh refinement was applied in the jet zones, and beyond a small transition layer the refined cell volume was equal to $V o l_{\min }$. The characteristics of the mesh cells are shown in Table 1.

Table 1. Characteristics of mesh cells

\begin{tabular}{|c|c|c|c|c|c|}
\hline Cell Type & \multicolumn{3}{|c|}{ Hexahedron } & \multicolumn{2}{c|}{ Polyhedron } \\
\hline Number of cells & $5.9 \mathrm{mln}$ & $10 \mathrm{mln}$ & $33 \mathrm{mln}$ & $4.5 \mathrm{mln}$ & $7 \mathrm{mln}$ \\
\hline$V_{\text {ool }}$ min, $\mathrm{m}^{3}$ & $10^{-6}$ & $10^{-6}$ & $3 \times 10^{-8}$ & $2 \times 10^{-10}$ & $2 \times 10^{-10}$ \\
\hline Vol $_{\max }, \mathrm{m}^{3}$ & $3 \times 10^{-3}$ & $4 \times 10^{-4}$ & $5 \times 10^{-4}$ & $2 \times 10^{-3}$ & $4 \times 10^{-3}$ \\
\hline$\left(\text { Volmin }_{\mathrm{min}}\right)^{1 / 3}, \mathrm{~mm}$ & 10 & 10 & 3 & 1 & 1 \\
\hline$\left(\text { Vol }_{\max }\right)^{1 / 3}, \mathrm{~mm}$ & 140 & 70 & 80 & 120 & 70 \\
\hline
\end{tabular}

For the hexahedral meshes, the cells adjacent to the solid walls have the same height of $20 \mathrm{~mm}$ (the only exception is the solid wall at the surface of the fan coils). Depending on the local flow features, this height corresponds to the normalized distance from the center of the first near-wall cell to the wall, $y^{+}$, in the range from the values lower than one up to values exceeding 40. Figure 4 gives an instantaneous $y^{+}$-distribution over several walls: zones with peak $y^{+}$-values correspond to the jet impingement regions at the side walls. Note that the $y^{+}$-values at the floor of the room are also relatively high, about 20. Polyhedral meshes ensured the $y^{+}$-values from the same range.

The computations were carried out using the resources of Peter the Great St.Petersburg Polytechnic University supercomputer center (scc.spbstu.ru). The computational resources used included 18 nodes of the Polytechnic RSC Tornado cluster. Each node has two CPUs Intel(R) Xeon(R) E5-2697v3 at $2.60 \mathrm{GHz}, 14$ cores each CPU. In total, up to 504 cores were used for the parallel computations.

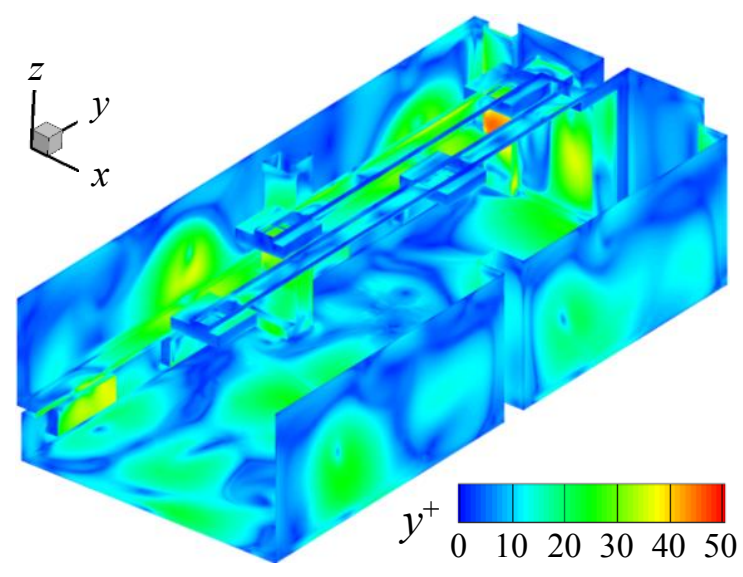

Fig. 4. An instantaneous distribution of the normalized distance from the center of the first computational cell to the wall (results for the mesh of 33 million cells)

\subsection{Solver settings}

Numerical solutions were obtained with the CFD package ANSYS Fluent 18.2 based on the finite volume method with the cell-centered variable arrangement. The second order scheme provided spatial discretization for convective terms. The second order pressure interpolation was used. Depending on the case, to link the continuity and momentum equations the iterative SIMPLEC or PISO methods were used. The non-iterative time advancement scheme (NITA) based on the fractional step method was chosen if possible to get a stable solution. The second order implicit time integration was used.

\section{Results and discussion}

\subsection{Time step sensitivity analysis}

The time step value, $\Delta t$, was varied: the values of $\Delta t=0.004 \mathrm{~s}, \Delta t=0.05 \mathrm{~s}$, and $\Delta t=0.5 \mathrm{~s}$ were used. For the coarse and baseline quasi-structured meshes, the value $\Delta t=0.004 \mathrm{~s}$ allowed to provide the Courant number values less than one over the entire computational domain. For these calculations, the NITA scheme was used. It was not possible to get solutions with the NITA method for the cases with $\Delta t=0.05 \mathrm{~s}$ and $\Delta t=0.5 \mathrm{~s}$, so that an iterative algorithm was applied.

To accumulate representative statistics, the total length of the time sample for each case was up to 15000 seconds. It was verified that the sample collected is sufficient to collect time-averaged data after the statistically developed regime is reached.

Figure 5 illustrates the sensitivity of the unsteady solution to the time step variation. Time evolution of $z$-velocity is given in Figure 5 at four monitoring points. The point $\mathrm{P}_{1}$ with the coordinates of $(2.1 \mathrm{~m}, 3.8 \mathrm{~m}, 2.75 \mathrm{~m})$ is located in the mixing layer region at the distance of $0.05 \mathrm{~m}$ from the fan coil \#2; the 
jet considered is directed to the positive $y$-coordinate. Three other points are placed along the line $x=3.2 \mathrm{~m}$, $z=1.6 \mathrm{~m}$ : point $\mathrm{P}_{2}$ at $y=1 \mathrm{~m}$, point $\mathrm{P}_{3}$ at $y=5.9 \mathrm{~m}$, and point $\mathrm{P}_{4}$ at $y=10.8 \mathrm{~m}$. These points are located in the occupied zone of the room at some distance from the jet core, where velocities are relatively weak.
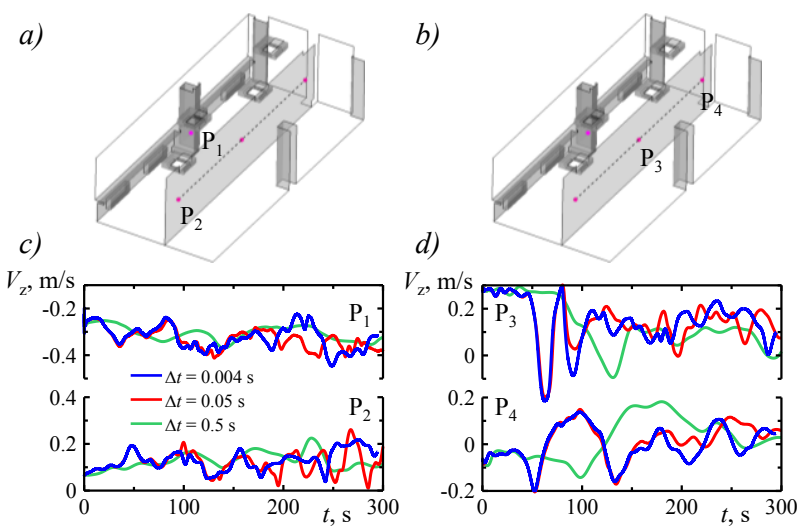

Fig. 5. Time step sensitivity analysis: (a), (b) positions of the monitoring points $\mathrm{P}_{1}-\mathrm{P}_{4}$; (c), (d) evolution of $z$-velocity (results for the mesh of 10 million cells)

A comparison of time-evolution plots computed with different time-step values illustrate noticeable dependence of the resolved frequencies. The difference in the amplitudes and frequencies of the resolved fluctuations with the time step is detected (see Figure 5 where the data for the baseline mesh are presented). However, as the RANS approach is used, the main result of the computations is in the mean quantities. For all three values of time step used, time-averaged flow characteristics are the same.

\subsection{Mesh sensitivity analysis}

Figure 6 illustrates the sensitivity of the time-averaged solution to the number of mesh cells variation; the case with quasi-structured meshes is shown. Mean velocity magnitude profiles along ten horizontal lines placed at two cross-sections are plotted in the figure. Positions of the lines with respect to the room height are given in Table 2; the range from $0.5 \mathrm{~m}$ to $2.75 \mathrm{~m}$ covers the entire height of the room.

Table 2. Vertical coordinates of lines used for profile visualization

\begin{tabular}{|c|c|c|c|c|c|}
\hline № & $a_{1}, a_{2}$ & $b_{1}, b_{2}$ & $c_{1}, c_{2}$ & $d_{1}, d_{2}$ & $e_{1}, e_{2}$ \\
\hline$z, \mathrm{~m}$ & 2.75 & 2.4 & 2 & 1 & 0.5 \\
\hline
\end{tabular}

The profiles at the section $x=2.1 \mathrm{~m}$ (Figure 6c) illustrate the propagation of four jets issued in the longitudinal direction. The first pair of jets located at $3.9 \mathrm{~m} \leq y \leq 4.9 \mathrm{~m}$ is issued from the supply sections of diffuser \#2, while the second pair of jets located at $9.8 \mathrm{~m} \leq y \leq 10.8 \mathrm{~m}$ is issued from the supply sections of diffuser \#4. The profiles at the section $y=4.4 \mathrm{~m}$ (Figure 6d) illustrate the propagation of two jets issued in the transversal direction from the supply sections of diffuser \#2.
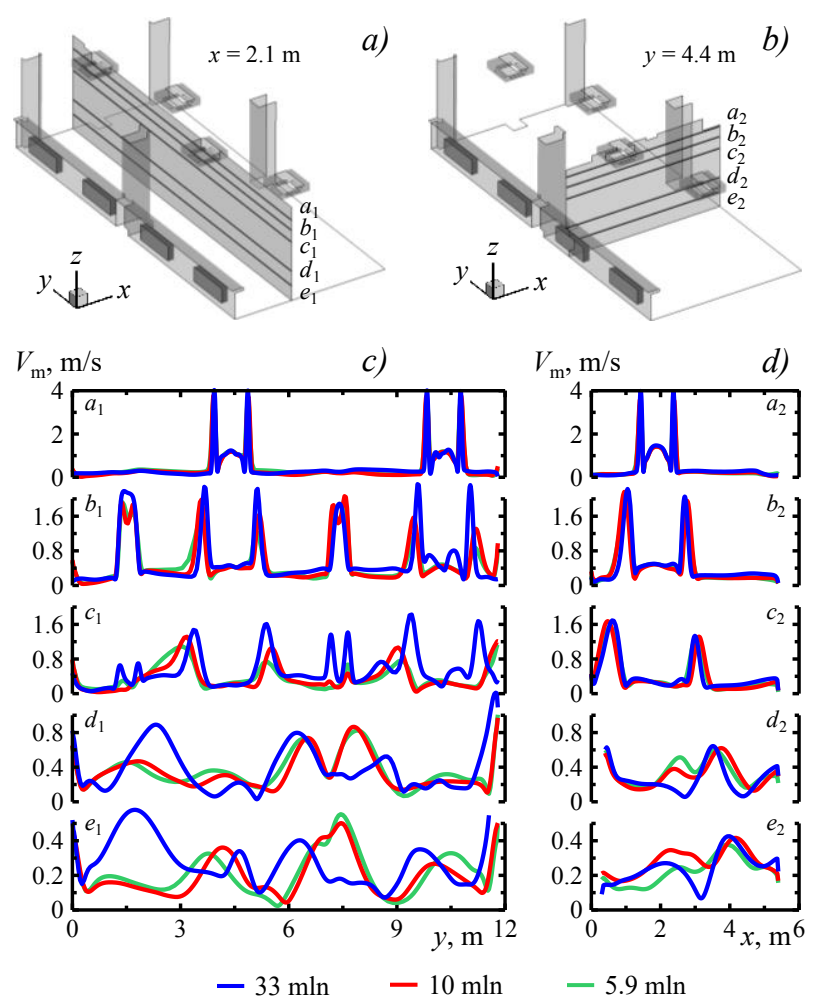

$-5.9 \mathrm{mln}$

Fig. 6. Mesh sensitivity analysis for the hexahedral meshes: (a), (b) positions of straight lines used for profile extraction from cross-sections (a) $x=2.1 \mathrm{~m}$ and (b) $y=4.4 \mathrm{~m}$; (c), (d) velocity magnitude profiles computed with three meshes

It is evident from the figure that there is strong mesh dependence of the time-averaged solution in the occupied zone, at least at $z<1 \mathrm{~m}$. The reason for that is in the insufficient spatial resolution provided by the coarse and baseline meshes in this region due to lack of computational cells there. Hence, prediction of jet propagation is sensitive to the spatial resolution at some distance from the initial jet region, and the jet decay is over predicted on the coarse and baseline meshes. The clustering of the quasi-structured grid used for the current simulation was mostly near the inlet and outlet sections of the diffusers, and did not cover enough the whole jet spreading at the angle of $45^{\circ}$. On the stage of the refined mesh generation, better resolution in the occupied zone was ensured, and more cells were used for the mixing layers reproduction.

For the polyhedral meshes used, less mesh sensitivity is detected. It is illustrated in Figure 7 where velocity profiles computed with two polyhedral meshes and the finest quasi-structured mesh are compared. The velocity profiles are almost the same for all cross-sections of the room; some differences could be observed at lines $e_{1}$ and $e_{2}$ that are located near the room floor.

Solution computed with the mesh of 33 million hexahedral cells could be treated as little sensitive to the mesh size. 


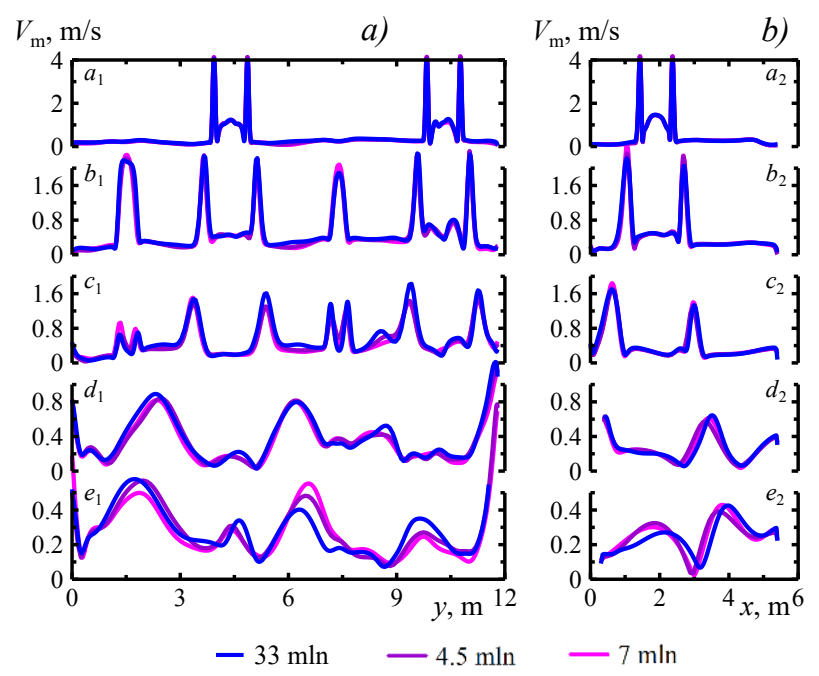

Fig. 7. Mesh sensitivity analysis for the polyhedral meshes: (a), (b) velocity magnitude profiles computed with three meshes

\subsection{Flow structure discussion}

In accordance with the conclusions from the mesh sensitivity analysis, the current section covers the results computed with the refined mesh of 33 million hexahedral cells. Figure 8 illustrates the global airflow pattern in the room with numerous jets: an instantaneous field of velocity magnitude is shown here at five vertical planes. Each transversal plane chosen crosses the corresponding diffuser at the mid-section; the values of the $y$-coordinate of the planes are $1.5 \mathrm{~m}, 4.4 \mathrm{~m}, 7.4 \mathrm{~m}$ and $10.3 \mathrm{~m}$. The longitudinal plane, $x=2.1 \mathrm{~m}$, crosses the diffusers \#2 and \#4, but not in the middle (the midcoordinate of these diffusers is $x=1.9 \mathrm{~m}$ ).

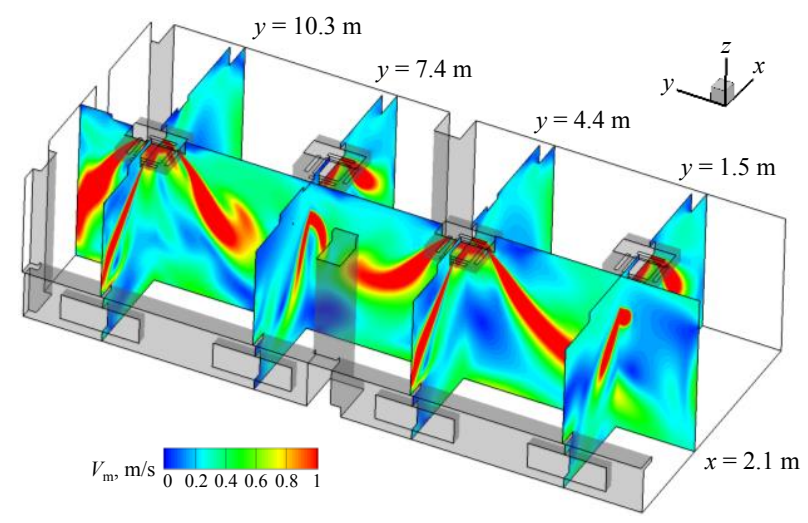

Fig. 8. Flow structure in the room: instantaneous fields of the velocity magnitude at several vertical sections

The air jets completely cover the upper part of the room, spreading almost freely at this region, the interaction between the jets is only at the distance from the diffusers. Despite of the identical arrangement of the supplied openings in all diffusers, the symmetry in the flow structure is not observed, at least in the instantaneous flow field analyzed. For example, detailed analysis of the velocity plot presented in Figure 8 points to different angles of the jet turn at the distance from the diffuser for the jets issued from two opposite supply sections of diffuser $\# 2$ in the positive and negative $y$ direction.

The mean velocity fields point to non-symmetrical distribution of the air jets even in the time-averaged flow structure. For example, it can be seen from Figure $7 \mathrm{~b}$ (lines $b_{2}$ and $c_{2}$ ) that the velocity profiles in the range of coordinates $0 \mathrm{~m}<\mathrm{x}<2 \mathrm{~m}$ and $2 \mathrm{~m}<\mathrm{x}<4 \mathrm{~m}$ differ much. That means that the propagation and, in particular, the degree of decay of the opposite jets from diffuser \#2 is slightly different.

Detailed analysis of the airflow pattern (with the attraction of detailed animations of flow structures) shows that all jets undergo quasi-periodic low-frequency oscillations. Figure 9 shows two instantaneous fields of the velocity magnitude at the same cross-section at two successive time instants. The section chosen for postprocessing crosses diffusers \#2 (in the left part of the plot) and \#4 (in the right part of the plot). Visible difference between two fields proves that there are intensive oscillations of the jets propagating from diffuser \#2; weaker oscillations of the jets from diffuser \#4 are also observed. Animations of flow structure in time prove that these oscillations are significantly threedimensional.

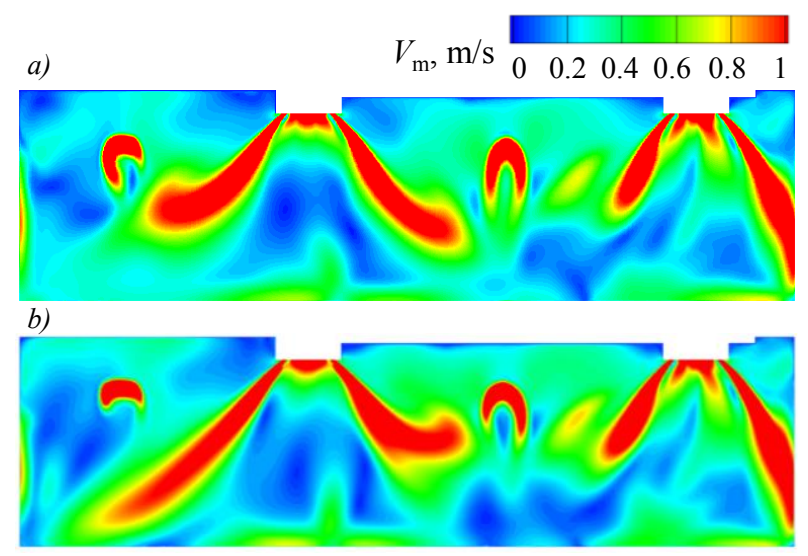

Fig. 9. Instantaneous fields of the velocity magnitude at vertical cross-section $x=2.1 \mathrm{~m}$ : a) $t=t_{0}$, b) $t=t_{0}+335 \mathrm{~s}$

Figure 10 illustrates $z$-velocity time-evolution and corresponding power spectra; data for three monitoring points $\mathrm{P}_{1}, \mathrm{P}_{2}$ and $\mathrm{P}_{3}$ are given (the data for the same points were presented in Figure 5); the plots present the entire sample corresponding to the statistically developed self-oscillating regime.

The evolution of $z$-velocity at point $\mathrm{P}_{3}$ clearly detects the low frequency oscillations that correspond to the pulsations of the jet propagating from diffuser \#3 in the negative $y$-direction (see the location of the point at Figure $5 \mathrm{a}, \mathrm{b}$ ). It is also visible in figure $10 \mathrm{~b}$ where the plots of the power spectral density (PSD) vs. frequency are shown for the same monitoring points. The main period of the oscillations is approximately equal to $T=750 \mathrm{~s}$ (that corresponds to the leading frequency of $1.33 \times 10^{-3} \mathrm{~Hz}$ visible in Figure $10 \mathrm{~b}$ ). The conclusion is that to detect this URANS-predicted frequency in experiments it is necessary to provide measurement samples of 30 minutes and even more. 
Figure 11 shows an instantaneous isosurface of velocity magnitude that reflects position of each jet core. The jets propagate periodically rotating with respect to the initial airflow direction. For example, jet propagating from the diffuser \#4 (diffuser located at the left side of Figure 11) in the negative direction of the $y$-axis.

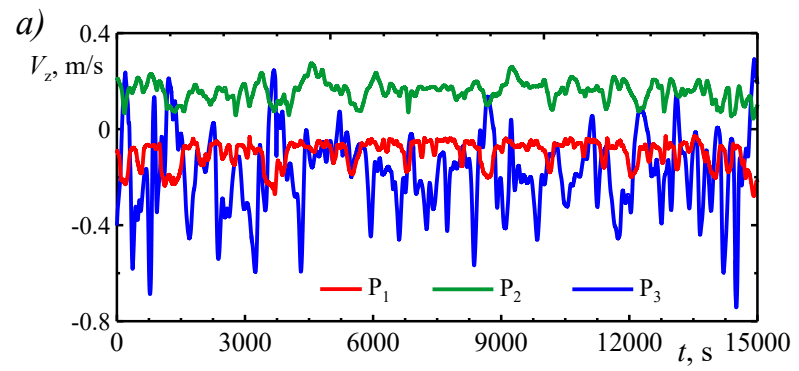

b)

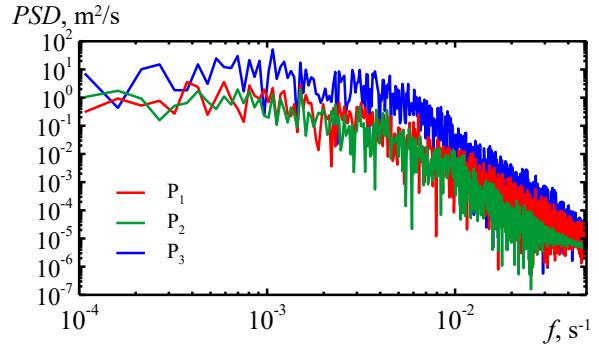

Fig. 10. a) Evolution of $z$-velocity and b) $z$-velocity pulsation spectra at monitoring points $\mathrm{P}_{1}, \mathrm{P}_{2}$ and $\mathrm{P}_{3}$

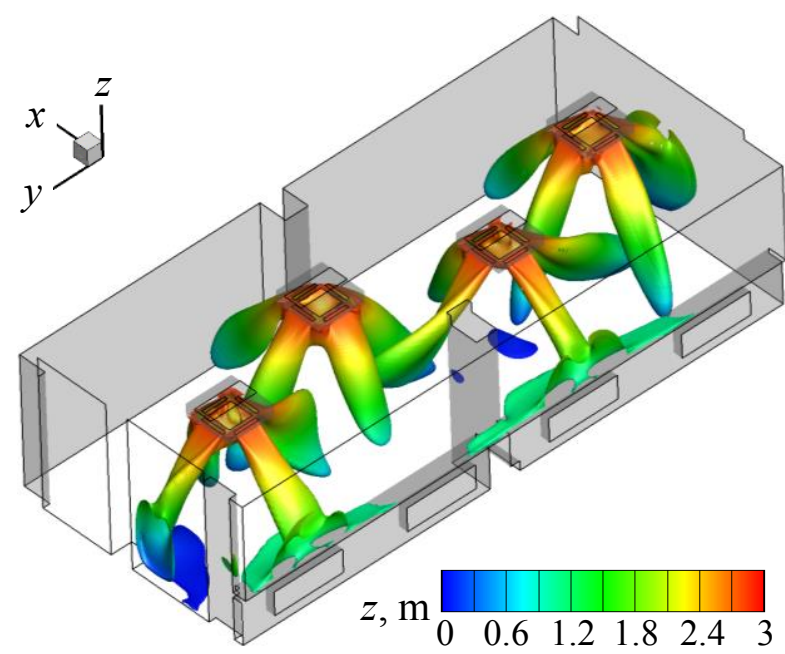

Fig. 11. Instantaneous isosurface of the velocity magnitude, $V_{\mathrm{m}}=0.65 \mathrm{~m} / \mathrm{s}$, colored by $z$-coordinate

Mean velocity profiles presented in Figures 6, 7 allow estimating the airflow structure, as well as the level of mean velocity in the occupied zone. The shape of velocity profiles at lines $d$ and $e$ almost repeat each other, and only the level of velocities changes. Note that due to high value of the flow rate adopted, the velocity values in the occupied zone are relatively high: at the height of $1 \mathrm{~m}$ that approximately corresponds to the position of the face of a seated person, velocity values vary from $0.2 \mathrm{~m} / \mathrm{s}$ to $0.8 \mathrm{~m} / \mathrm{s}$.

Local high-velocity regions in the occupied zone impose restrictions on the spatial resolution there on the measurement stage. The distribution of the measurement points must be enough to detect the local velocity peaks, and it is recommended to keep the distance between the neighboring points less than $0.2 \mathrm{~m}$.

\section{Conclusions}

Results of the Unsteady Reynolds-Averaged NaviesStokes (URANS) simulation of ventilation in an isothermal room of a simple rectangular form with numerous jets supplied from ceiling diffusers are presented and discussed. Simplified boundary conditions with equal flow rates at each supply opening and uniform velocity distribution at the supply opening surface were set. Calculations of airflow at the Reynolds number of $2 \times 10^{4}$ were carried out using the ANSYS Fluent 18.2 software with the standard $k$ - $\varepsilon$ turbulence model chosen.

Results of time step and mesh sensitivity analyses are presented. It was shown that time-averaged velocity fields do not depend on the time step in the range used. Hexahedral meshes of more than 30 million cells or polyhedral meshes of about 5 million cells provide the same quality of the solution.

The calculations revealed low-frequency large-scale oscillations of jets propagating from the supply diffusers, with typical periods of about 600-800 seconds. Pronounced spatial non-uniformity of the velocity field in the occupied zone was detected. The information on the computed air velocity distributions and their temporal behavior could be useful for air velocity measurements planning and, in particular should be considered on the stage of the sensor positions distribution.

The work was supported by the Russian Foundation for Basic Research (grant No. 18-58-18011) and by Bulgarian Science Fund of the Ministry for Education and Science (grant № ДНТС/Русия 02/11 from 15.06.2018).

\section{References}

1. ANSI/ASHRAE Standard 62.1-2016. "Ventilation for Acceptable Indoor Air Quality" (2016)

2. CEN Standard EN 13779-2007. "Ventilation for nonresidential buildings, performance requirements for ventilation and room conditioning systems" (2007)

3. S.K. Wang. Handbook of air conditioning and refrigeration (2001)

4. W. Liu, J. Wen, J. Chao, W. Yin, C. Shen, D. Lai, C.H. Lin, J. Liu, H. Sun, Q. Chen. Atmospheric Environment 56, pp. 33-44 (2012)

5. R. You, J. Chen, C.H. Lin, D. Wei, Q. Chen. Building and Environment 111, pp. 110-122 (2017)

6. A. Limane, H. Fellouah, N. Galanis. International Journal of Heat and Mass Transfer 109, pp. 862878 (2017)

7. P. Koper, B. Lipska, W. Michnol. Architecture Civil Engineering Environment 3, pp. 95-103 (2010) 
8. M. Deza, B. Ganapathysubramanian, S. He, U. Passe. "High fidelity CFD modeling of natural ventilation in a solar house," Proc. of the ASME 2015 International Mechanical Engineering Congress and Exposition (IMECE2015, November 13-19, 2015, Houston, Texas), pp. 1-7 (2015)

9. A. Palmowska, B. Lipska. Building and Environment 108, pp. 171-182 (2016)

10. C.H. Son, E.M. Smirnov, N.G. Ivanov, D.S. Telnov. "Integrated Computational Fluid Dynamics ventilation model for the International Space Station" Proc. of the 35th Int. Conf. on Environmental Systems (Rome, Italy, July 11-14 2005) SAE Paper 2005-01-2794, pp. 1-7 (2005)

11. C.H. Son, E.H, Turner, E.M. Smirnov, N.G. Ivanov, D.S. Telnov. "Integrated Computational Fluid Dynamics carbon dioxide concentration study for the International Space Station" Proc. of the 35th Int. Conf. on Environmental Systems (Rome, Italy, July 11-14 2005) SAE Paper 2005-01-2795, pp. 1-6 (2005)

12. C.H. Son, N.G. Ivanov, D.S. Telnov, E.M. Smirnov. "Numerical Study of Ammonia Leak and Dispersion in the International Space Station" Proc. of the 42nd Int. Conf. on Environmental Systems (San Diego, California, USA, July 15-19 2012) AIAA Technical Paper AIAA 2012-3582, pp 392-401 (2012)

13. J.O. Hinze. Turbulence (1975)

14. Y. Li, P.V. Nielsen. Indoor Air 21 pp $442-453$ (2011)

15. U. Piomelli. Phil. Trans. R. Soc. A 372 pp. 1-13 (2014)

16. M. Hurnik, M. Blaszczok, Z. Popiolek, Building and Environment 93 pp 319-330 (2015)

17. P.V. Nielsen, A. Restivo, J.H. Whitelaw, ASME J. Fluids Engineering 100 pp 291-298 (1978)

18. J.C. Bennetsen. "Numerical simulation of turbulent airflow in livestock buildings," Ph.D thesis 205 p. (1999)

19. L.K. Voight. "Navier-Stokes simulations of airflow in rooms and around a human body," Ph.D thesis 169 p. (2001)

20. N. Ivanov, M. Zasimova. J. of Physics: Conf. Series 1038 012136, pp. 1-6 (2018)

21. N. Ivanov, M. Zasimova, E. Smirnov, D. Markov. "Evaluation of mean velocity and mean speed for test ventilated room from RANS and LES CFD modeling," Proc. of the EENVIRO 2018 Conf. (ClujNapoca, Romania, October 9-13 2018) E3S Web of Conferences 8502004 (2019)

22. J.D. Posner, C.R. Buchanan, D. Dunn-Rankin, Energy and Buildings 35 pp. 515-526 (2003)

23. C. Heschl, Y. Tao, K. Inthavong, J. Tu. Building Simulation 9 (2) pp. 213-220 (2016)

24. Z.F. Tian, J.Y. Tu, G.H. Yeoh, R.K.K. Yuen. Building and Environment 42 pp 3483-3492 (2007)
25. H. Mocikat, T. Gürtler, H. Herwig. Experiments in Fluids 34 pp 442-448 (2003)

26. N.G. Ivanov, S.V. Egorov. "3D ventilation airflow in a test facility: validation of Reynolds-Averaged Navier-Stokes approach application," in Proc. of the 12th International Conference on Air Distribution in Rooms (Roomvent 2011), pp. 1-8 (2011)

27. M. Hurnik, M. Blaszczok, Z. Popiolek, Data in Brief 5 pp 213-7 (2015)

28. M. Zasimova and N. Ivanov. AIP Conference Proceedings 1959050033 (2018)

29. N.G. Ivanov and M.A. Zasimova. "Large Eddy Simulation of airflow in a room with a sidewall jet: comparison with benchmark test data for occupied zone," in Proc. of Roomvent \& Ventilation 2018: Excellent Indoor Climate and High Performing Ventilation pp 319-24 (2018) 